\title{
The Role of Antenatal and Postnatal Maternal Bonding in Infant Development:
}

\section{A Systematic Review and Meta-Analysis}

Genevieve A. Le Bas ${ }^{\mathrm{a}}$, George J. Youssef ${ }^{\mathrm{ab}}$, Jacqui A. Macdonald ${ }^{\mathrm{abc}}$, Larissa Rossen ${ }^{\text {ef }}$, Sam J. Teague ${ }^{\text {a }}$, Emily J. Kothe ${ }^{\text {a }}$, Jennifer E. McIntosh ${ }^{\text {ac }}$, Craig A. Olsson ${ }^{\text {abcd, }}$ and Delyse M. Hutchinson ${ }^{\text {abce* }}$

a. Deakin University Geelong, Centre for Social and Early Emotional Development, School of Psychology, Faculty of Health, Victoria, Australia

b. Centre for Adolescent Health, Murdoch Children's Research Institute, Royal Children's Hospital, Melbourne, Victoria, Australia

c. Department of Paediatrics, University of Melbourne, Royal Children's Hospital, Melbourne, Victoria, Australia

d. Melbourne School of Psychological Sciences, University of Melbourne, Parkville, Victoria, Australia

e. National Drug and Alcohol Research Centre, University of New South Wales, Sydney, Australia

f. School of Psychiatry, Faculty of Medicine, University of New South Wales, Sydney, Australia

\section{*Corresponding Author}

Name Dr Delyse Hutchinson

Address Centre for Social and Early Emotional Development, School of Psychology, Faculty of Health, Deakin University, Burwood, Victoria, Australia, 3125

Phone $+61425218628$

Email delyse.hutchinson@deakin.edu.au

\section{Conflicts of Interest}

Genevieve A. Le Bas, George J. Youssef, Jacqui A. Macdonald, Larissa Rossen, Sam J. Teague, Emily J. Kothe, Jennifer E. McIntosh, Craig A. Olsson, and Delyse M. Hutchinson declare that they have no conflict of interest.

This is the author manuscript accepted for publication and has undergone full peer review but has not been through the copyediting, typesetting, pagination and proofreading process, which may lead to differences between this version and the Version of Record. Please cite this article as doi: $10.1111 /$ SODE.12392

This article is protected by copyright. All rights reserved 


\section{Data Availability Statement}

The raw data file and code used to conduct the meta-analysis can be found here: https://osf.io/s5rqm/.

\section{Funding}

This research did not receive any specific grant from funding agencies in the public, commercial, or not-for-profit sectors.

\section{Contributors}

G.L. conceptualised and designed the study, completed data acquisition, contributed to data analysis and interpretation, and wrote and submitted the manuscript.

G.Y. conceptualised and designed the study, supervised data acquisition, completed data analysis, contributed to the interpretation of data, supervised the write-up of results, and revised the manuscript.

J.A.M. supervised data acquisition, contributed to data analysis and interpretation, and revised the manuscript.

L.R. completed data acquisition, contributed to data interpretation, and revised the manuscript.

S.T. completed data acquisition, contributed to data interpretation, and revised the manuscript.

E.K. supervised data acquisition, contributed to data interpretation, and revised the methods and results sections of the manuscript.

J.E.M. critically reviewed and revised the manuscript for important intellectual content.

C.O. critically reviewed and revised the manuscript for important intellectual content.

D.H. conceptualised and designed the study, coordinated and supervised data acquisition, data analysis, and data interpretation, and revised the manuscript.

All authors approved the final manuscript as submitted and agree to be accountable for all aspects of the work. 
PROF. DELYSE HUTCHINSON (Orcid ID : 0000-0003-3221-7143)

Article type : Review

\section{ABSTRACT}

The purpose of this study was to systematically review the empirical literature on maternal bonding and associations with infant physical, psychological, and social development. Nineteen articles met inclusion criteria and were included in a qualitative synthesis (79 effect sizes); fifteen articles were suitable for aggregation in a series of 14 meta-analyses (51 effect sizes). All mean effects were in the expected direction, with higher maternal bonding contributing to infant developmental outcomes, including higher attachment quality $(r=.35)$ and parent-reported lower colic rating $(r=.22)$, easier temperament $(r=19)$, and positive infant mood $(r=.27)$. Consistent with theoretical explanatory models, the review provides support for the hypothesis that maternal bonding plays a role in fostering more optimal infant development. The review also identifies a paucity of empirical work on this topic and provides directions for future research.

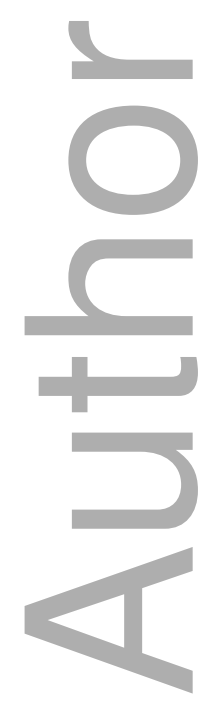

\section{Introduction}

This article is protected by copyright. All rights reserved 
The powerful affectional bond between a mother and her child first develops during pregnancy, permeating maternal behaviour and care through the antenatal and postnatal periods (Condon, 1993; Korja et al., 2010). A positive affectional connection between mother and infant facilitates the provision of care by the mother, and the maintenance of an affective environment in which the infant feels safe to explore, learn, and develop age-appropriate autonomy. Theoretically, the connection is reciprocal and vital for optimal infant development (Ainsworth, Blehar, \& Waters, 2014; Winnicott, 1965). To date, no systematic meta-analytic reviews of which we are aware provide empirical data on these associations; yet such research has potential to guide prevention and targeted intervention strategies to improve maternal bonding and in turn, infant development.

Maternal bonding refers to a mother's self-reported emotional connection to her child. During pregnancy, mothers typically develop internalised representations of their unborn child accompanied by an affectional tie to the fetus, often referred to as antenatal maternal bonding (Condon, 1993). A positive bond during pregnancy is associated with engaging in behaviours of affiliation and affection, such as talking to the unborn child, and positive health practices, such as abstaining from drugs (Condon, 1993; Cranley, 1981; Van der Zalm, 1995). Postnatal maternal bonding refers to a mother's emotional tie to her infant. Maternal perceptions of a positive postnatal bond are indicated by a mother's felt pleasure in interacting with her infant, developing competence in her own capacity to understand and meet her infant's needs, and acceptance and tolerance of the demands of the maternal role (Condon \& Corkindale, 1998). Maternal perceptions of the postnatal affectional bond reflect pleasure in maternal-infant interactions, which influence an infant's capacity for affective signalling (Bornstein, 1989; Grant, McMahon, Reilly, \& Austin, 2010). Higher bonding is theoretically expressed through behaviours such as maternal sensitivity and emotional availability (Feldman, Weller, Leckman, Kuint, \& Eidelman, 1999), which invite interaction and encourage healthy social-emotional behaviours (e.g., interest, touch, smiles, play, adaptivity, approach, emotional regulation) and development.

Condon (1993) suggests that a mother's internalised representation of her child is increasingly elaborated upon during pregnancy, with antenatal bonding providing structure for the subsequent development of postnatal bonding (Condon \& Corkindale, 1998). In a sample of 372 mothers, Rossen et al. (2016) found that higher antenatal bonding prospectively predicted higher postnatal bonding at all pregnancy trimesters, after controlling for a range of demographic and postnatal covariates. Although postnatal bonding appears to have its roots in antenatal bonding, birth marks the introduction of additional complexities; a 
mother is required to integrate her perceptions of motherhood and her child with new realities, including the characteristics of her infant (Condon, 1993; Solomon \& George, 1996). Given the complexities unique to each period, it is important to examine how the maternal bond in both phases might shape development in infancy.

Maternal bonding is underpinned by the integration of oxytocin and dopamine in striatum. Oxytocin and dopamine systems support multiple motivational behaviours, including social orienting and seeking, and contact maintaining. Connectivity among these systems during bond formation enables plasticity of the brain reward system and reorganisation of neural networks (Feldman, 2017). This process of the mother forming a selective and enduring bond with her child is accompanied by mental, emotional, and behavioural changes that facilitate physical and psychological proximity (Feldman et al., 1999; Insel \& Young, 2001; Kendrick, 2000). During interactions, mothers and infants have been shown to demonstrate synchronised nonverbal behaviour (i.e., gaze, affect, vocal, touch), heart rate, oxytocin response, cortisol response to stress, and brain oscillations in alpha and gamma rhythms (Feldman, 2017). "The capacity to give and receive love and maintain long-term bonds is increasingly recognised as key to human thriving, impacting well-being, positive outlook in the face of adversity, physical health, and better aging" (Feldman, 2017, p. 94). Individual differences related to the timing and intensity of bonding remain unclear, though an amalgam of psychological, interpersonal, and biological mechanisms is likely. For example, perinatal depression and anxiety are associated with bonding, which may be related to difficulties with emotion regulation being a common feature amongst these symptom profiles (Brockington, 2004; Rossen et al., 2016). Stable personality factors may also contribute to self-reported bonding, with research indicating links between emotional stability and extraversion and stronger maternal-infant bonds (de Cock et al., 2016).

The constructs of bonding and attachment are often confused or conflated. This is compounded by the fact that many bonding assessment instruments are referred to as “attachment” measures (Condon, 1993; Condon \& Corkindale, 1998; Cranley, 1981). Indeed, researchers often refer to a mother's felt bond toward her infant as attachment, as this relationship relates to the development of feelings of love and protection toward the infant (Walsh, 2010). Bonding and attachment are interrelated constructs, however they are motivated by different goals and governed by different behavioural systems. Bowlby (1969, p. 377) argues "There is a strong case... for restricting the term attachment to the behaviour typical of the child to parent and the behavioural system responsible for it, and to avoid using 
it to describe the complementary behaviour and behavioural system of the parent". More specifically, bonding is a function of the Caregiving Behavioural System, serving to protect and comfort the infant in times of distress or threat. The Attachment Behavioural System is activated when an individual feels threat or distress and seeks to elicit care and protection. Attachment represents the patterning of the infant's behaviour and expectations of the mother's caregiving responses assessed observationally (Ainsworth, 1989; Cassidy \& Shaver, 2016). In contrast, bonding specifically refers to the mother's self-reported emotional connection to her child. This confusion in the literature regarding the definition and measurement of bonding may explain why numerous studies have established associations between infant attachment and development (Ainsworth, 1989; Bowlby, 1969; Cassidy \& Shaver, 2016; Groh, Fearon, van IJzendoorn, Bakermans- Kranenburg, \& Roisman, 2017), yet few studies have explored the influence that bonding may have on infant social-emotional development.

Branjerdporn, Meredith, Strong, and Garcia (2017) recently synthesised the available research on a mother's felt emotional connection to her infant during pregnancy and infant developmental outcomes. While the authors termed this construct maternal-infant attachment, the conceptual content within this review closely approximates our definition of antenatal bonding. Data were qualitatively synthesised according to developmental domain: infant temperament $(n=5)$, adaptive behaviour $(n=2)$, and milestone attainment $(n=1)$. Their study found evidence that higher antenatal bonding was associated with more optimal infant development in infants aged 0-26 months, with outcomes including: normal levels of activity (i.e., not overactive; Davoudi, 2012); regular physiologic functions, such as sleep and hunger (Priel \& Besser, 2000); approach to new stimuli (Davoudi, 2012; Priel \& Besser, 2000); adaptable temperament (Davoudi, 2012; Priel \& Besser, 2000); less intense temperament (i.e., less high energy responses; Davoudi, 2012; Priel \& Besser, 2000); positive overall mood (Davoudi, 2012; White, Wilson, Elander, \& Persson, 1999); attentive temperament (Davoudi, 2012); higher sensory threshold (i.e., more stimulation required to evoke a response; Davoudi, 2012); lower colic rating (Escallier, 1995); and increased developmental milestone attainment (Alhusen, Hayat, \& Gross, 2013). Only one association was identified that linked higher maternal bonding with a less optimal outcome - lower (total) sleep time in infancy (Speltzer, O'Beirne, \& Bishop, 2008). Taken together, the authors found evidence to suggest that higher maternal bonding was generally associated with more optimal infant development, but concluded that results should be interpreted with caution due to the limited number and low quality of many of the available studies. 
The Branjerdporn et al. (2017) review provided a much needed synthesis of the extant research linking antenatal bonding and infant development; however, three specific limitations are noted here. First, the review was confined to associations between antenatal bonding and infant development. Examination of both the antenatal and postnatal periods remains important, given: (1) the complexities unique to each period (Condon, 1993; Rossen et al., 2017; Solomon \& George, 1996), and (2) the paucity of available research on bonding and infant development. Second, the review reported only on statistical significance and direction of effects, rather than reporting specific correlation values (i.e., no information provided on the magnitude of associations) nor any meta-analytic estimate of the population effect. Third, the review restricted the search to a narrow array of developmental outcome domains, and within these, did not have a sufficient number of studies for meta-analysis. Addressing these limitations would allow more studies to be retrieved and for the results to be examined through meta-analysis.

\section{The Current Review}

The aims of this systematic review and meta-analysis were to: (1) identify studies that prospectively examined the impact of antenatal or postnatal maternal bonding on infant developmental outcomes; (2) extract effect sizes for these associations; (3) group similar infant developmental outcomes together and assess the design and quality of the studies included; and, (4) conduct a meta-analysis for each infant outcome domain (depending on study availability), including information on the strength and direction of observed effects. Outcomes of maternal bonding were restricted to the period of infancy (the first 24 months of postnatal life) given: (1) it is proximal to the measurement of antenatal and postnatal bonding; (2) it is a critical time of development characterised by marked physiological, physical, and psychological change; and, (3) early life events influence the child's capacity to cope with its environment in later life (Bornstein, 2014; Fraser et al., 2012; Gluckman, Hanson, \& Mitchell, 2010). Finally, we note that whilst paternal bonding is also likely to play a role in infant social-emotional development both directly, and indirectly via the partner relationship (e.g., fathers play an important role in supporting the mother's wellbeing; Barker, Iles, \& Ramchandani, 2017), we chose to focus on maternal bonding given the limited research available on paternal bonding and child development.

\section{Method}

\section{Data Sources}

The method adhered to Preferred Reporting Items for Systematic Reviews and MetaAnalyses (PRISMA) guidelines (Moher, Liberati, Tetzlaff, \& Altman, 2009). The systematic 
search procedure included an electronic and grey literature search, as well as forward and backward citation analysis. The following electronic databases were searched for peerreviewed articles (including theses): PsycINFO (EBSCOhost platform); MEDLINE Complete (EBSCOhost platform); Informit; CINAHL Complete (EBSCOhost platform); and, Embase. Search terms were developed for four concepts: maternal, bonding, infant, and, longitudinal. Search terms for the four concepts included both free text terms and subject headings. Including subject headings allowed for increased specification of search terms; including key free text terms allowed for records without subject headings to be captured (for example, records recently added to the database). Due to discrepancies in terminology, we included a wide range of search terms to describe bonding, including terms such as 'attachment'. See Supporting Information Table S1 for search terms and Table S2 for search syntax (for all databases). Search terms on infant developmental outcomes were not included so as to retrieve records on all possible outcomes. No limits were applied to searches so that records without categorisation were captured. The grey literature search involved the examination of the first 100 citations (10 pages) in a Google search. It also involved contacting authors of studies where the relevant variables were included in an article but the associations were not reported. Finally, Web of Science was used to review citation and reference lists of: (1) included studies; and, (2) relevant reviews on maternal bonding.

Eligibility criteria. Eligible studies were identified by first screening titles and abstracts, and then reviewing full text. For both stages of screening, G.L. screened $100 \%$ of articles and L.R. screened 10\% of articles for reliability analysis; some articles also required discussion [G.L., G.Y., L.R., J.A.M., and D.H.] to determine whether they met eligibility criteria. Studies were included in the review if they met the following criteria: (1) available in English; (2) human sample; (3) empirical and peer-reviewed (i.e., conference abstracts, commentaries, editorials, literature reviews, and case studies were excluded; theses were included); (4) included a measure of maternal bonding (self-reported or inferred through interview) during the antenatal or postnatal period (gestation-24 months postpartum); (5) included a measure of developmental outcome during infancy (0-24 months); (6) longitudinal design, where maternal bonding was tested as the predictor and infant development as the outcome, with a minimum of one month between assessment time-points; (7) not a parenting intervention study, unless findings of a control group were reported (because parenting intervention may impact bonding; Feldman, Eidelman, Sirota, \& Weller, 2002; Willinger, Diendorfer-Radner, Willnauer, Jörgl, \& Hager, 2005); and, (8) reported (or provided on request) an unadjusted correlation between maternal bonding and later infant outcome. 
Measurement of maternal bonding. We [G.L., J.A.M, L.R., D.H.] assessed (with consensus agreement) whether purported bonding measures were a measure of the mother's felt bond to her child, or a measure of another related yet different construct (for example, infant or adult attachment). Consistent with Condon and Corkindale (1998) and Lamb (1974), we argue that measures of antenatal and postnatal maternal bonding require a focus on the mother's self-reported affective bond to her child (self-report measure or inferred through interview), rather than factors likely to mediate or indicate the presence of bonding, such as maternal attitudes, beliefs, or behaviours. We reviewed 77 potential measures of maternal bonding. Of these 77 measures, 47 were excluded because they were assessed as measuring a different construct; the remaining 30 measures progressed to item-level analysis. These 30 measures were compared at the item-level with prototypical measures of bonding to determine the suitability of the article being included (17 further measures were excluded). At this stage, we identified 13 measures of maternal bonding. Only eight measures were included in the current review, as some studies were excluded for reasons unrelated to the bonding measure. The bonding measures are described in Supporting Information Table S3, including information on the psychometrics from the original measure development studies.

\section{Data Extraction}

Using a standardised, pilot-tested extraction sheet, data were extracted and collated from studies that met inclusion criteria $(\mathrm{N}=19)$. Data were extracted by G.L. and independently cross referenced by G.Y. for all studies. Data extracted included: study characteristics; maternal bonding measure and time of assessment; infant outcome measure and time of assessment; and effect size, $\mathrm{p}$ value, and sample size for the association between maternal bonding and infant outcome. Standard effect sizes (Pearson's r) were extracted from 14 studies. For the remaining five studies, effect sizes were converted from Cohen's d or chisquare to Pearson's $r$ using standard formulas (Borenstein, Hedges, Higgins, \& Rothstein, 2011). Where multiple publications reported on the same sample and finding, preference was given to studies that reported on total bonding (as opposed to only including bonding subscales), and then studies with the larger sample size.

\section{Screening for Meta-Analysis Eligibility}

With consensus agreement, we [G.L., G.Y., J.A.M., D.H.] grouped studies for metaanalyses according to infant developmental outcomes. For each infant outcome able to be grouped (association with bonding reported on in two or more studies), a meta-analysis was conducted. Some outcomes clearly measured the same construct, and were easily grouped; these included: attachment secure/insecure classifications only, colic, and the domains of 
temperament (activity, adaptability, approach, distractibility, intensity, mood, persistence, rhythmicity, sensory threshold). We also included three additional aggregate 'superordinate' meta-analyses examining bonding and: (1) attachment quality (secure/insecure and disorganised/not-disorganised classifications); (2) social-emotional outcomes (exploratory activity, negative affect, positive affect, solicitation of attention, social-emotional competence, externalising behaviours, and internalising behaviours); and, (3) temperamental difficulty (where available, all effects for each temperamental domain were included; otherwise, we included the effect for total temperamental difficulty). These superordinate meta-analyses looked at the broadest categories possible and likely had more heterogeneity; however, they allowed us to obtain meta-analytic associations using a larger number of effects. We considered including superordinate analyses for cognitive/language and physical/motor outcomes, however, decided through consensus agreement, that the available infant outcomes were too heterogeneous. A total of 15 studies reporting 51 suitable effect sizes were eligible for aggregation in the series of 14 meta-analyses, described in Table 1. Findings of outcomes unable to be grouped (association with bonding reported in only one study for a specific domain) were included in qualitative synthesis but excluded from the meta-analysis. Supporting Information Table S4 provides detail on all studies included in quantitative and qualitative synthesis.

\section{Data Analysis}

Meta-analysis. The raw data file and code used to conduct the meta-analysis can be found here: https://osf.io/s5rqm/. For meta-analyses that involved only one effect size per study, we used the Metafor package v1.9.8 (Viechtbauer, 2010) in R software v3.3.1 (R Core Team, 2015) and included random effects to account for study heterogeneity. For metaanalyses that involved more than one effect per study (i.e., the social-emotional and temperamental difficulty superordinate meta-analyses), we used a robust variance metaanalysis approach using the Robumeta package in R (v3.3.2; Fisher \& Tipton, 2015). This technique accounts for multiple dependent effects via robust estimations of effect size weights and standard errors (Hedges, Tipton, \& Johnson, 2010; Tanner-Smith, Tipton, \& Polanin, 2016). Between-study heterogeneity was tested using the $\mathrm{I}^{2}$ statistic, providing a percentage estimate of the amount of total variability in effect size estimates that can be attributed to heterogeneity among the true effects (Viechtbauer, 2010). We caution overinterpretation, however, due to the small number of effect sizes identified per meta-analysis (Sterne et al., 2011). Further, although we intended to test for bias through visual inspection of funnel plots and using Egger's test of asymmetry (Egger, Smith, Schneider, \& Minder, 
1997), the small number of effects meant that test power was too low to distinguish chance from real asymmetry (Sterne et al., 2011). Published guidelines were used to interpret metaanalytic effect sizes, where $r=0.1$ is small, 0.3 moderate, and 0.5 large (Cohen, 1992).

Risk of bias assessment. A components approach was adopted to assess risk of bias in this review, whereby the research in each article was rated on individual criteria that reflect the methodological risk of bias (Higgins, Thompson, Deeks, \& Altman, 2003). These criteria included: maternal bonding measure, type (self-report or interview), and time of assessment; and infant outcome measure, type (maternal-report or administered), and time of assessment. These criteria were recorded during the data extraction process and sensitivity and moderation analyses were conducted to examine whether findings were robust to the quality of the methodological approaches of the articles included (Higgins et al., 2003). Moderation analysis was only conducted when there were at least two effects per level of the moderator variable (i.e., two effects for one maternal bonding measure, and two effects for another). When a moderation was not possible, we used sensitivity analyses to examine whether removal of the effects from studies that employed different methodological approaches influenced the magnitude of the meta analytic effect (when at least two effects were remaining to be analysed).

\section{Results}

\section{Study Selection}

The PRISMA diagram is shown in Figure 1. Of the 19,813 studies identified in the electronic and grey literature search, 19 were included in qualitative synthesis, and 15 were included in the meta-analyses. Notably, using the Prevalence-Adjusted and Bias-Adjusted Kappa statistic (PABAK; Byrt, Bishop, \& Carlin, 1993), inter-rater reliability was high for both title and abstract screening (PABAK = .94) and full text screening $(\mathrm{PABAK}=.91)$.

$* * * *$ Figure $1 * * * *$

\section{Qualitative Synthesis}

Included studies were published between 1979-2017, with the majority published from 2008 onwards $(n=12)$. Most samples were recruited from either the United States of America $(n=7)$ or Canada $(n=4)$. Remaining samples were recruited from the Netherlands $(\mathrm{n}=2)$, and the United Kingdom, Israel, Sweden, Italy, Germany and Australia (each n=1). Average maternal age at Time 1 ranged from 21 to 34 years $(M=28.03, \mathrm{SD}=3.9)$. Sample sizes that were used for correlations within each study ranged from 34 to $499(\mathrm{M}=145.16$, 
$\mathrm{SD}=115.89$; sum of samples across all included studies $=2,758)$. Study characteristics are further described in Supporting Information Table S4, along with study predictors and outcomes, and findings specific to their association (for all 19 included studies).

Fourteen studies investigated the impact of antenatal bonding only on infant outcomes, three studies investigated postnatal bonding only; and two included both antenatal and postnatal bonding. Antenatal bonding was assessed using a range of measures, including the Maternal Antenatal Attachment Scale (MAAS; $n=5)$, Maternal Fetal Attachment Scale (MFAS; $n=4)$, Prenatal Attachment Inventory (PAI; $n=3$ ), Working Model of the Child Interview (WMCI; $\mathrm{n}=2$ ), Working Model of the Child Interview - Disrupted (WMCI-D; $\mathrm{n}=$ 1), and Social Distance Scale $(n=1)$. These measures were all administered in the second or third trimester of pregnancy, which could be because bonding quality is likely stronger towards the end of pregnancy (Rossen et al., 2016). Measures of postnatal bonding included the Maternal Postnatal Attachment Scale (MPAS; $\mathrm{n}=3$ ), Postpartum Bonding Questionnaire (PBQ; $\mathrm{n}=1)$, and WMCI-D $(\mathrm{n}=1)$. These measures were administered from 2-12 months postpartum.

A range of infant outcomes were identified, and these were assessed from birth to 24 months postpartum. Multiple studies investigated attachment, colic, social-emotional outcomes, overall temperamental difficulty, and the temperamental domains of activity, adaptability, approach, distractibility, intensity, mood, persistence, rhythmicity, and sensory threshold. These findings comprised a total of 51 independent effect sizes that were able to be included in meta-analyses.

Infant outcomes with only one reported effect size (28 of 79 available effects) were not included in meta-analysis. These were: adverse neonatal outcomes; overall developmental milestone attainment; executive function; behaviour during assessment; cognitive development; motor development; language development; and sleep. Further, one total temperamental difficulty effect size was excluded due to the study Della Vedova (2014) also reporting individual effect sizes for each temperamental domain. Of these studies, there was evidence to support associations between higher maternal bonding and more optimal infant development across outcomes including: neonatal development (Alhusen, Gross, Hayat, Rose, \& Sharps, 2012); child development (Alhusen et al., 2013); executive function (de Cock et al., 2017); motor development (Sierau et al., 2016); and language development (Sierau et al., 2016). These effects sizes ranged from small to large, with the larger effects sizes belonging to neonatal development $(\mathrm{r}=.52)$ and child development $(\mathrm{r}=.59)$. However, we note some studies found evidence for links between higher maternal bonding and less 
optimal infant development, with outcomes including: less engaged behaviour during assessment (Sierau et al., 2016), lower cognitive and language development (Sierau et al., 2016), and less total sleep time at one week postpartum (Speltzer et al., 2008). These effect sizes were all small ( $\mathrm{r}=-0.1$ to -.28$)$. There was no evidence in support of relations between maternal bonding and other variables in these independent studies. Nevertheless, it is difficult to make any firm inferences on these qualitative findings, given that the majority of statistically significant effects belong to the one study (Sierau et al., 2016). As such, metaanalytic estimates, which account for all available data provide a more appropriate summary measure of effects and we await future research to provide insights into the relations between bonding and these additional independent variables.

\section{Meta-Analysis}

Results from the series of 14 meta-analyses are provided in Table 1. All mean effects were in the expected direction, where higher maternal bonding predicted more optimal infant developmental outcomes. The evidence did not support the null hypothesis for four metaanalyses: bonding (antenatal and postnatal) and attachment (superordinate); antenatal bonding and colic; bonding (antenatal and postnatal) and temperamental difficulty (superordinate); and antenatal bonding and infant mood. Namely, higher bonding was associated with higher quality infant attachment (superordinate), with a moderate effect size $(\mathrm{N}$ effects $=4$ from 4 studies; combined $\mathrm{N}$ of participants $=477 ; \mathrm{r}=.35,95 \%, \mathrm{CI}: .16-.52)$. Second, higher antenatal bonding predicted lower colic rating, with a small effect size (N effects $=2$ from 2 studies; combined $\mathrm{N}$ of participants $=141 ; \mathrm{r}=.22,95 \% \mathrm{CI}$ : .03-.39). Third, higher bonding was associated with easier infant temperament (superordinate), with a small effect size $(\mathrm{N}$ effects $=36$ from 7 studies; combined $\mathrm{N}$ of participants $=749 ; \mathrm{r}=.19$, 95\% CI: .03-.34). Last, within the specific temperament domains, higher antenatal bonding predicted more positive overall infant mood, with a small-moderate effect size $(\mathrm{N}$ effects $=5$ from 5 studies; combined $\mathrm{N}$ of participants $=480 ; \mathrm{r}=.27,95 \% \mathrm{CI}$ : .07-.45). There was little evidence for non-zero effects for the remaining 10 meta-analyses, with effect sizes ranging from small-moderate $(r=.09-.30)$. These investigated attachment security (secure/insecure classifications only); social-emotional outcomes (superordinate); and the temperamental domains of activity, adaptability, approach, distractibility, intensity, persistence, rhythmicity, and sensory threshold. Of note, confidence intervals for heterogeneity statistics are not available for robust variance meta-analyses, and for the standard meta analyses these CIs were large. As such interpretation of heterogeneity is cautioned given the small number of effect sizes in each meta-analysis. 
$* * * *$ Table $1 * * * *$

\section{Sensitivity and Moderation Analyses}

Few moderation or sensitivity analyses were possible due to the low number of effects available per meta-analysis. With respect to moderation analyses, where possible we examined the bonding measure employed, time of exposure assessment (antenatal versus postnatal), and time of outcome assessment (infant age). Of the analyses that could be conducted, the meta-analytic associations between bonding and attachment (superordinate), temperamental difficulty (superordinate), and the temperamental domains of approach, intensity, and rhythmicity, were not moderated by maternal bonding measure. However, there was a difference in the associations between bonding and infant mood $(\mathrm{p}=.019)$; the magnitude was weaker in studies that included the MAAS $(\mathrm{k}=2, \mathrm{r}=.07,95 \% \mathrm{CI}:-.05$, $0.19)$, relative to the PAI $(\mathrm{k}=2, \mathrm{r}=.44,95 \% \mathrm{CI}: 0.11, .69)$. We conducted a moderation analysis examining the timing of the maternal bonding assessment and infant socialemotional outcomes (superordinate). There was a difference $(\mathrm{p}=.027)$ in the magnitude of relation between bonding and social-emotional outcomes, with the antenatal period $(\mathrm{k}=2, \mathrm{r}=$ $.03,95 \% \mathrm{CI}: .03, .03)$ found to be lower than the postnatal period $(\mathrm{k}=2, \mathrm{r}=.21,95 \% \mathrm{CI}$ : $.11, .49)$. However, when examining the meta-analytic correlation within these two periods separately, there was only weak evidence for a non-zero correlation between postnatal bonding and social-emotional outcomes $(\mathrm{p}=.076)$. We examined infant outcome time of assessment for all three superordinate analyses, but found no significant relationships. No other moderation analyses were able to be performed.

With respect to sensitivity analyses, when including only studies that used the MPAS $(\mathrm{k}=2, \mathrm{r}=0.21,95 \% \mathrm{CI}:-.11, .49)$, the meta-analytic correlation between bonding and socialemotional outcomes (superordinate) was not different to the magnitude of the original meta-analytic correlation (see Table 1). When including only those studies that used the PAI, there was an increase in the meta-analytic correlation between bonding and the temperamental domains of activity $(\mathrm{k}=2, \mathrm{r}=0.3825,95 \% \mathrm{CI}:-.4, .84)$, distractibility $(\mathrm{k}=2$, $\mathrm{r}=.26,95 \% \mathrm{CI}: .04, .46)$, persistence $(\mathrm{k}=2, \mathrm{r}=.31,95 \% \mathrm{CI} .15, .45)$, and sensory threshold $(\mathrm{k}=2, \mathrm{r}=.27,95 \% \mathrm{CI}-.69, .88)$. However, we note that the confidence intervals for these were large and overlapping with the original estimated effect size. Moreover, we believe any differences were largely attributable to the sensitivity analyses comprising the study by 
Davoudi (2012), which was found to have quite strong effect sizes. No other sensitivity analyses could be performed.

\section{Discussion}

\section{Summary of Evidence}

This systematic review and meta-analysis informs a significant gap in knowledge on the association of maternal bonding with developmental outcomes in infancy. Our review identified a paucity of empirical work on this topic, with the available studies being not only small (by sample size), but also highly heterogeneous in measurement, making it difficult to draw firm conclusions about aetiological relations. Within this context, all mean metaanalysed effects linking bonding to infant development were in a positive direction, albeit effect sizes varied, ranging from negligible to moderate in magnitude. Four meta-analysed effects were statistically significant. Specifically, higher maternal bonding was correlated with: (1) higher quality attachment (superordinate meta-analysis; $\mathrm{N}$ effects $=4 ; \mathrm{r}=.35$ ) and parent-reported lower colic rating ( $\mathrm{N}$ effects $=2 ; \mathrm{r}=.22$ ), easier temperament (superordinate meta-analysis; $\mathrm{N}$ effects $=36 ; \mathrm{r}=.19)$, and positive infant $\operatorname{mood}(\mathrm{N}$ effects $=5 ; \mathrm{r}=.27)$.

\section{Interpretation of Findings}

The current review reported on unadjusted correlations, providing support for an association between higher maternal bonding and more optimal infant developmental outcomes. Results suggest that whilst infant development is multiply informed, a mother's perception of her felt emotional connection to her child is an important factor related to higher infant attachment quality and mood, and lower infant temperament difficulty and colic rating. Findings align with theoretical perspectives, which suggest that developmental outcomes are influenced by shared affective states with the caregiver (Greenspan \& Shanker, 2009). Infants have limited capacity to regulate negative emotions, and as such, learn strategies for controlling and managing emotions through interactions with caregivers (Bornstein, 1989; Grant et al., 2010). Maternal bonding may be reflected in pleasure in maternal-infant interactions, which may lead to higher infant attachment quality and mood, and lower infant temperament difficulty and colic rating. It is important to acknowledge that these developmental outcomes likely overlap; for example, maternal reports of colic may be accompanied by reports of difficult temperament. Further, given all maternal and infant variables included in the meta-analyses were assessed via maternal self-report (excluding attachment), results may be influenced by maternal self-reporting bias or social desirability.

It is notable that effect sizes were generally small. A mother's subjective experience may not impact developmental outcomes as strongly as the infant's real and observable 
experience of her caregiving behaviours, particularly under stress. Importantly, most included studies examined antenatal bonding; it is possible that stronger associations exist between postnatal bonding and infant development, given its direct ties to maternal-infant interactions. Findings may reflect developmental consolidation of experience dependent neural networks (Bornstein, 2014; Schore \& McIntosh, 2011), with early bonding experiences having a cascading influence on later bonding, and later stages of development.

Despite all meta-analytic effects being in the expected direction, there was little evidence to suggest that antenatal bonding predicted the remaining domains of temperament (i.e. activity, adaptability, approach, distractibility, intensity, persistence, rhythmicity, and sensory threshold). It is likely that the small number of effects available for each metaanalysis resulted in low statistical power ( $\mathrm{N}$ effects $=3-4)$. Nonetheless, bonding may have more of an influence on infant outcomes that are dependent on maternal-infant interactions and affective signalling (e.g., mood and colic), compared with non-social-affective domains (e.g., temperamental activity and intensity). It is possible that factors other than the mother's perceived bond may be more important in influencing these outcomes.

There was limited evidence to suggest that bonding predicted the superordinate social-emotional outcome variable $(\mathrm{r}=.13)$. This result may be explained by the small number of available effects and heterogeneity in infant outcomes. Notably, one study focused on infant behaviour in free-play with the mother (exploratory activity, negative affect, positive affect, and solicitation of attention; Huth- Bocks, Theran, Levendosky, \& Bogat, 2011), another focused on externalising and internalising behaviours (Sierau et al., 2016), and the final study investigated social-emotional competence (Mason, Briggs, \& Silver, 2011). Further research including key measures of social-emotional development (such as the socialemotional scales of the Ages and Stages Questionnaire or Bayley Scales of Infant and Toddler Development) is recommended to enable firmer conclusions to be made regarding its association with bonding. Given the evidence provided for associations between bonding and other social-affective outcomes (e.g., mood and colic), it is possible that bonding exerts a similar impact on overall infant social-emotional development. In particular, postnatal bonding may implicate infant social-emotional development through its expression in maternal-infant interactions. On the other hand, positive social and emotional attributes may lead the mother to feel more emotionally connected to her child. In sum, further research is required to disentangle the complex and interrelated pathways that are likely to exist between maternal bonding, infant behaviour, and subsequent development in infancy and beyond. 


\section{Limitations in the Literature}

Whilst the majority of findings demonstrated positive associations between maternal bonding and infant social and emotional development, our results confirm the need for further evidence to strengthen the inferences that can be made about the relationship between these two constructs. Consistent with the findings of Branjerdporn et al. (2017), results highlighted the paucity of research on antenatal bonding and infant development ( $\mathrm{n}$ studies $=$ 16). It was perhaps more surprising, however, that only five studies were identified in relation to the postnatal bond. To minimise the risk that articles were not found in the search, a range of search terms were used to describe maternal bonding. While this resulted in a large number of records ( $\mathrm{N}$ records $=19,813$ ), screening reduced this number markedly. It is notable that the large majority of articles investigated attachment, or maternal factors likely to mediate or indicate the presence of bonding (such as maternal attitudes or behaviours), rather than the mother-infant affectional bond. Of those studies that did investigate maternal bonding, the majority focused on either the trajectory of bonding across the antenatal and postnatal periods, or links to other maternal characteristics (rather than to infant outcomes).

Of the studies that did investigate maternal bonding and infant outcomes $(\mathrm{N}$ studies $=$ 77): 38 studies did not include maternal bonding as a prospectively assessed predictor variable (i.e., the studies were cross-sectional, or treated maternal bonding as an outcome variable); three studies were parenting intervention studies that did not report control group findings; 12 studies did not report on (or were unable to provide on request) the association between maternal bonding and infant outcomes, as it was not the focus of the study; and, five studies reported the same findings as other studies already included on our review (leaving 19 studies that met inclusion criteria). Taken together, this highlights a significant gap in the extant literature. Indeed, it would appear that further research is needed on all of the infant outcomes examined in the current review, as each outcome was investigated in no more than five studies.

The paucity of research on maternal bonding and infant development represents a significant gap in knowledge and affects the strength of inferences that can be drawn from the current meta-analyses. Future research should include prospective assessments with multiple waves across the antenatal and postnatal periods to enhance knowledge of the relationship between antenatal and postnatal bonding, and to explore whether these constructs differentially predict infant developmental outcomes. It would also be valuable to explore the independent contribution of bonding to infant social-emotional development, by including other predictors, such as infant attachment and maternal sensitivity. Replicating and 
extending the available research would allow for findings to be pooled, and more meaningful conclusions to be drawn on the relations between antenatal bonding, postnatal bonding, and infant development.

This review further highlights confusion in the available literature on the measurement of maternal bonding. Indeed, we [G.L., J.A.M., L.R., D.H.] determined through a process of extensive review whether purported bonding measures were measures of the mother's felt bond to her developing fetus or infant, or measures of another related yet different construct (e.g., maternal competence, attitudes, adult attachment experiences). In numerous cases (30 measures), we made comparisons at the item-level with prototypical measures of bonding to determine the suitability of an article being included. In other cases, measures were excluded because whilst bonding (or an aspect of bonding) was measured, so too were other maternal characteristics, yet only total correlated scores were provided by the authors. Several articles were also excluded because they assessed the mother's feelings about pregnancy or being a mother, rather than the mother's affective bond to her child.

\section{Strengths and Limitations of the Current Review}

We extended the findings of Branjerdporn et al. (2017) by including studies on both the antenatal and postnatal mother-to-infant bond, which is important given the complexities unique to each period. Further, including postnatal studies meant that we identified a notable gap in research, with only five studies identified on the postnatal bond. We also employed a systematic and extensive search strategy (outlined in Method), which meant that we included 19 relevant studies, compared to the eight studies included in the Branjerdporn et al. (2017) review. For example, we contacted authors where relevant variables were included but not reported on. We also extended the findings of Branjerdporn et al. (2017) by reporting on the magnitude of associations, and by including a series of meta-analyses to quantitatively evaluate and statistically combine results of comparable studies.

We outline three limitations of the current review. The main limitation is that majority of the meta-analyses included only 2-5 effects, with confidence intervals for heterogeneity estimates being large. Related to this, it was also difficult to make inferences about how methodological differences between studies may have influenced results since few meaningful moderation and sensitivity analyses could be conducted due to the limited number of available effects. As such, we recommend a cautious approach to interpretation of findings given that the reliability of the estimated meta-analytic effect sizes may be affected by unknown study differences (Schroll, Moustgaard, \& Gøtzsche, 2011). Finally, for both stages of screening (titles/abstracts and full text), only one author screened $100 \%$ of articles, 
with a second author screening $10 \%$ of articles for reliability analysis. This decision was a practical one given the large number of articles retrieved due to our extensive search strategy. Although this approach is considered standard and valid, full double screening may have increased reliability (Haddaway \& Westgate, 2018).

\section{Conclusions and Recommendations}

The current review offers two key contributions to the literature on maternal bonding and infant development. First, results highlight limitations in the extant literature and directions for future research. These include inconsistency in the definition and measurement of bonding which has created some confusion in the literature. Further, there is a marked paucity of research on bonding and infant social-emotional development (particularly postnatal bonding), and a lack of high-quality longitudinal research. Within this context, and consistent with theoretical explanatory models, the review provides some support for the hypothesis that antenatal and postnatal bonding are important in determining more optimal development in a number of infant outcomes. Notably, this includes higher infant attachment quality and mood, and lower infant temperament difficulty and colic rating. There is a clear need for longitudinal studies that include multiple antenatal and postnatal waves assessing bonding and a range of infant developmental outcomes. Including multiple waves would enable isolation of effects (i.e., timing and dose) informing preventative intervention and treatment approaches to bonding related difficulties and associated infant developmental sequelae, across the antenatal and postnatal periods.

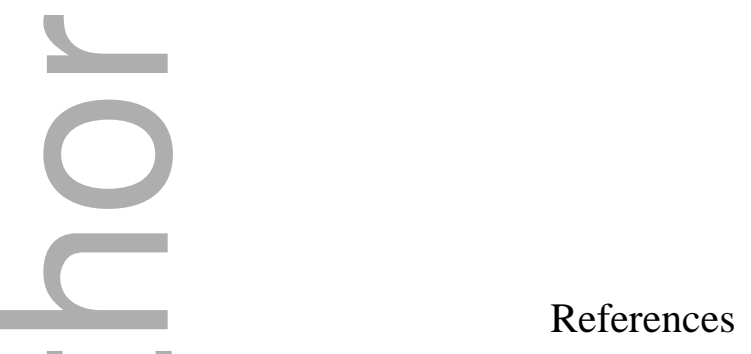

Ainsworth, M. (1989). Attachments beyond infancy. American Psychologist, 44, 709. doi:10.1037/0003-066X.44.4.709

Ainsworth, M., Blehar, M., \& Waters, E. (2014). Patterns of attachment: A psychological study of the strange situation. New York, USA: Psychology Press.

Alhusen, J. L., Gross, D., Hayat, M. J., Rose, L., \& Sharps, P. (2012). The role of mental health on maternal- fetal attachment in low- income women. Journal of Obstetric, Gynecologic \& Neonatal Nursing, 41, E71-E81. doi:10.1111/j.15526909.2012.01385.x 
Alhusen, J. L., Hayat, M. J., \& Gross, D. (2013). A longitudinal study of maternal attachment and infant developmental outcomes. Archives of Women's Mental Health, 16, 521529. doi:10.1007/s00737-013-0357-8

Barker, B., Iles, J. E., \& Ramchandani, P. G. (2017). Fathers, fathering and child psychopathology. Currrent Opinion in Psychology, 15, 87-92. doi:10.1016/j.copsyc.2017.02.015

Benoit, D., Parker, K. C., \& Zeanah, C. H. (1997). Mothers' representations of their infants assessed prenatally: Stability and association with infants' attachment classifications. Journal of Child Psychology and Psychiatry, 38, 307-313. doi:10.1111/j.14697610.1997.tb01515.x

Borenstein, M., Hedges, L. V., Higgins, J. P., \& Rothstein, H. R. (2011). Introduction to meta-analysis. West Sussex, UK: John Wiley \& Sons.

Bornstein, M. H. (1989). Sensitive periods in development: Structural characteristics and causal interpretations. Psychological Bulletin, 105, 179. doi:10.1037//00332909.105.2.179

Bornstein, M. H. (2014). Human infancy... And the rest of the lifespan. Annual Review of Psychology, 65, 121-158. doi:10.1146/annurev-psych-120710-100359

Bowlby, J. (1969). Attachment and loss, vol. 1: Attachment. New York, US: Basic Books.

Branjerdporn, G., Meredith, P., Strong, J., \& Garcia, J. (2017). Associations between maternal-foetal attachment and infant developmental outcomes: A systematic review. Maternal and Child Health Journal, 21, 540-553. doi:10.1007/s10995-016-2138-2

Brockington, I. (2004). Postpartum psychiatric disorders. The Lancet, 363, 303-310. doi:10.1016/S0140-6736(03)15390-1

Byrt, T., Bishop, J., \& Carlin, J. B. (1993). Bias, prevalence and kappa. Journal of clinical epidemiology, 46, 423-429. doi:10.1016/0895-4356(93)90018-V

Cassidy, J., \& Shaver, P. R. (2016). Handbook of attachment, third edition: Theory, research, and clinical applications. New York, US: Guliford Press.

Cohen, J. (1992). A power primer. Psychological Bulletin, 112, 155. doi:10.1037/h0045186

Condon, J. T. (1993). The assessment of antenatal emotional attachment: Development of a questionnaire instrument. British Journal of Medical Psychology, 66, 167-183. doi:10.1111/j.2044-8341.1993.tb01739.x

Condon, J. T., \& Corkindale, C. J. (1998). The assessment of parent-to-infant attachment: Development of a self-report questionnaire instrument. Journal of Reproductive and Infant Psychology, 16, 57-76. doi:10.1080/02646839808404558 
Cranley, M. S. (1981). Development of a tool for the measurement of maternal attachment during pregnancy. Nursing Research, 30, 281-284. doi:10.1097/00006199198109000-00008

Crawford, A., \& Benoit, D. (2009). Caregivers' disrupted representations of the unborn child predict later infant-caregiver disorganized attachment and disrupted interactions. Infant Mental Health Journal: Official Publication of The World Association for Infant Mental Health, 30, 124-144. doi:10.1002/imhj.20207

Davoudi, R. (2012). The relationship between prenatal attachment and postnatal infant temperament. (Unpublished doctoral dissertation). Pacifica Graduate Institute, California, US.

de Cock, E. S., Henrichs, J., Klimstra, T. A., Maas, A. J. B., Vreeswijk, C. M., Meeus, W. H., \& van Bakel, H. J. (2017). Longitudinal associations between parental bonding, parenting stress, and executive functioning in toddlerhood. Journal of Child and Family Studies, 26, 1723-1733. doi:10.1007/s10826-017-0679-7

de Cock, E. S., Henrichs, J., Vreeswijk, C. M., Maas, A. J., Rijk, C. H., \& van Bakel, H. J. (2016). Continuous feelings of love? The parental bond from pregnancy to toddlerhood. Journal of Family Psychology, 30, 125. doi:10.1037/fam0000138

Della Vedova, A. (2014). Maternal psychological state and infant's temperament at three months. Journal of Reproductive and Infant Psychology, 32, 520-534. doi:10.1080/02646838.2014.947472

Egger, M., Smith, G. D., Schneider, M., \& Minder, C. (1997). Bias in meta-analysis detected by a simple, graphical test. British Medical Journal, 315, 629-634. doi:10.1136/bmj.315.7109.629

Escallier, L. A. (1995). Prenatal predictors of infant colic: Maternal-fetal attachment, maternal state anxiety and maternal hope. (Unpublished doctoral dissertation). Adelphi University, New York, US.

Feldman, R. (2017). The neurobiology of human attachments. Trends in Cognitive Sciences, 21, 80-99. doi:10.1016/j.tics.2016.11.007

Feldman, R., Eidelman, A. I., Sirota, L., \& Weller, A. (2002). Comparison of skin-to-skin (kangaroo) and traditional care: Parenting outcomes and preterm infant development. Pediatrics Springfield, 110, 16-26. doi:10.1542/peds.110.1.16

Feldman, R., Weller, A., Leckman, J. F., Kuint, J., \& Eidelman, A. I. (1999). The nature of the mother's tie to her infant: Maternal bonding under conditions of proximity, 
separation, and potential loss. The Journal of Child Psychology and Psychiatry and Allied Disciplines, 40, 929-939. doi:10.1111/1469-7610.00510

Fisher, Z., \& Tipton, E. (2015). Robumeta: An r-package for robust variance estimation in meta-analysis. Retrieved from https://arxiv.org/abs/1503.02220.

Fraser, A., Macdonald-Wallis, C., Tilling, K., Boyd, A., Golding, J., Davey Smith, G., . . Ness, A. (2012). Cohort profile: The avon longitudinal study of parents and children: Alspac mothers cohort. International Journal of Epidemiology, 42, 97-110. doi:10.1093/ije/dys066

Gluckman, P. D., Hanson, M. A., \& Mitchell, M. D. (2010). Developmental origins of health and disease: Reducing the burden of chronic disease in the next generation. Genome Medicine, 2, 14. doi:10.1186/gm135

Grant, K.-A., MeMahon, C., Reilly, N., \& Austin, M.-P. (2010). Maternal sensitivity moderates the impact of prenatal anxiety disorder on infant mental development. Early Human Development, 86, 551-556. doi:10.1016/j.earlhumdev.2010.07.004

Greenspan, S. I., \& Shanker, S. (2009). The first idea: How symbols, language, and intelligence evolved from our primate ancestors to modern humans. Cambridge, MA, US: Da Capo Press.

Groh, A. M., Fearon, R. P., van IJzendoorn, M. H., Bakermans- Kranenburg, M. J., \& Roisman, G. I. (2017). Attachment in the early life course: Meta- analytic evidence for its role in socioemotional development. Child Development Perspectives, 11, 7076. doi:10.1111/cdep.12213

Haddaway, N. R., \& Westgate, M. (2018). Predicting the time needed to conduct an environmental systematic review or systematic map: Analysis and decision support tool. Conservation Biology, 33, 434-443. doi:10.1101/303073

Hall, R., Hoffenkamp, H., Tooten, A., Braeken, J., Vingerhoets, A., \& Van Bakel, H. (2015). Longitudinal associations between maternal disrupted representations, maternal interactive behavior and infant attachment: A comparison between full-term and preterm dyads. Child Psychiatry \& Human Development, 46, 320-331. doi:10.1007/s10578-014-0473-3

Hammarberg, K. (2006). The experience of birth and early mothering after assisted conception. (Unpublished doctoral dissertation). The University of Melbourne, Melbourne, Australia. Retrieved from https://minervaaccess.unimelb.edu.au/bitstream/handle/11343/39184/67115_00002870_01_Thesis.p $\underline{\text { df? } \text { sequence }=1}$ 
Hedges, L. V., Tipton, E., \& Johnson, M. C. (2010). Robust variance estimation in meta- regression with dependent effect size estimates. Research Synthesis Methods, 1, 39-65. doi:10.1002/jrsm.5

Higgins, J. P., Thompson, S. G., Deeks, J. J., \& Altman, D. G. (2003). Measuring inconsistency in meta-analyses. British Medical Journal, 327, 557-560. doi:10.1136/bmj.327.7414.557

Huth- Bocks, A. C., Theran, S. A., Levendosky, A. A., \& Bogat, G. A. (2011). A social- contextual understanding of concordance and discordance between maternal prenatal representations of the infant and infant-mother attachment. Infant Mental Health Journal, 32, 405-426. doi:10.1002/imhj.20304

Insel, T. R., \& Young, L. J. (2001). The neurobiology of attachment. Nature Reviews Neuroscience, 2, 129. doi:10.1006/hbeh.2001.1691

Jones, H. E. (1996). Predictors of a mother's feelings and perceptions about her infant: From pregnancy to postpartum. (Unpublished doctoral dissertation). California School of Professional Psychology, California, US.

Kendrick, K. M. (2000). Oxytocin, motherhood and bonding. Experimental Physiology, 85, 111s-124s, doi:10.1111/j.1469-445X.2000.tb00014.X

Korja, R., Ahlqvist-Björkroth, S., Savonlahti, E., Stolt, S., Haataja, L., Lapinleimu, H., . . . Group, P. S. (2010). Relations between maternal attachment representations and the quality of mother-infant interaction in preterm and full-term infants. Infant Behavior and Development, 33, 330-336. doi:10.1016/j.infbeh.2010.03.010

Lamb, M. E. (1974). A defense of the concept of attachment. Human Development, 17, 376-385. doi:10.1159/000271359

Mason, Z., Briggs, R., \& Silver, E. J. (2011). Maternal attachment feelings mediate between maternal reports of depression, infant social-emotional development, and parenting stress. Journal of Reproductive and Infant Psychology, 29, 382-394. doi:10.1080/02646838.2011.629994

Moher, D., Liberati, A., Tetzlaff, J., \& Altman, D. G. (2009). Preferred reporting items for systematic reviews and meta-analyses: The prisma statement. Annals of Internal Medicine, 151, 264-269. doi:10.1016/j.jclinepi.2009.06.005

Parfitt, Y., Ayers, S., Pike, A., Jessop, D., \& Ford, E. (2014). A prospective study of the parent-baby bond in men and women 15 months after birth. Journal of Reproductive and Infant Psychology, 32, 441-456. doi:10.1080/02646838.2014.956301 
Pinkus, J. (1979). A prospective study of relationships between prenatal maternal parameters and early infant development. (Unpublished doctoral dissertation). University of Toronto, Toronto, Canada.

Priel, B., \& Besser, A. (2000). Adult attachment styles, early relationships, antenatal attachment, and perceptions of infant temperament: A study of first- time mothers. Personal Relationships, 7, 291-310. doi:10.1111/j.1475-6811.2000.tb00018.x

Rossen, L., Hutchinson, D., Wilson, J., Burns, L., Allsop, S., Elliott, E. J., . . Mattick, R. P. (2017). Maternal bonding through pregnancy and postnatal: Findings from an australian longitudinal study. American Journal of Perinatology, 34, 808-817. doi:10.1055/s-0037-1599052

Rossen, L., Hutchinson, D., Wilson, J., Burns, L., Olsson, C. A., Allsop, S., . . Mattick, R. P. (2016). Predictors of postnatal mother-infant bonding: The role of antenatal bonding, maternal substance use and mental health. Archives of Women's Mental Health, 19, 609-622. doi:10.1007/s00737-016-0602-z

Schore, A., \& McIntosh, J. (2011). Family law and the neuroscience of attachment, part i. Family Court Review, 49, 501-512. doi:10.1111/j.1744-1617.2011.01387.x

Schroll, J. B., Moustgaard, R., \& Gøtzsche, P. C. (2011). Dealing with substantial heterogeneity in cochrane reviews: Cross-sectional study. BMC medical research methodology, 11, 22-22. doi:10.1186/1471-2288-11-22

Sierau, S., Dähne, V., Brand, T., Kurtz, V., von Klitzing, K., \& Jungmann, T. (2016). Effects of home visitation on maternal competencies, family environment, and child development: A randomized controlled trial. Prevention Science, 17, 40-51. doi:10.1007/s11121-015-0573-8

Solomon, J., \& George, C. (1996). Defining the caregiving system: Toward a theory of caregiving. Infant Mental Health Journal, 17, 183-197. doi:10.1002/(SICI)10970355(199623)17:3<183::AID-IMHJ1>3.0.CO;2-Q

Speltzer, P., O’Beirne, M., \& Bishop, A. (2008). Prenatal attachment and postnatal infant sleep. Journal of Prenatal \& Perinatal Psychology \& Health, 23, 33-48. Retrieved from https://www.questia.com/library/journal/1P3-1752488201/prenatal-attachmentand-postnatal-infant-sleep.

Sterne, J. A., Sutton, A. J., Ioannidis, J. P., Terrin, N., Jones, D. R., Lau, J., . . Schmid, C. H. (2011). Recommendations for examining and interpreting funnel plot asymmetry in meta-analyses of randomised controlled trials. British Medical Journal, 343, d4002. doi:10.1136/bmj.d4002 
Tanner-Smith, E. E., Tipton, E., \& Polanin, J. R. (2016). Handling complex meta-analytic data structures using robust variance estimates: A tutorial in r. Journal of Developmental and Life-Course Criminology, 2, 85-112. doi:10.1007/s40865-0160026-5

Van der Zalm, J. E. (1995). Accommodating a twin pregnancy: Maternal processes.

Acta Geneticae Medicae et Gemellologiae: Twin Research, 44, 117-133. doi:10.1017/S0001566000001781

Viechtbauer, W. (2010). Conducting meta-analyses in $r$ with the metafor package. Journal of Statistical Software, 36, 1-48. doi:10.18637/jss.v036.i03

Walsh, J. (2010). Definitions matter: If maternal-fetal relationships are not attachment, what are they? Archives of Women's Mental Health, 13, 449-451. doi:10.1007/s00737-0100152-8

White, M. A., Wilson, M. E., Elander, G., \& Persson, B. (1999). The swedish family: Transition to parenthood. Scandinavian Journal of Caring Sciences, 13, 171-176. doi:10.1111/j.1471-6712.1999.tb00536.x

Willinger, U., Diendorfer-Radner, G., Willnauer, R., Jörgl, G., \& Hager, V. (2005). Parenting stress and parental bonding. Behavioral Medicine, 31, 63-72. doi:10.3200/BMED.31.2.63-72

Winnicott, D. (1965). The maturational processes and the facilitating environment: Studies in the theory of emotional development. London, UK: Routledge.

\section{List of Figures}

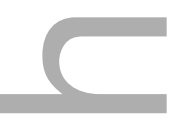

Figure 1. PRISMA diagram.

Note.

${ }^{a}$ The 121 records here refer to those identified through later citation analysis or Google search.

${ }^{\mathrm{b}}$ The exclusion criteria are listed in hierarchical order - the first exclusion criterion that a record met was considered its 'reason for exclusion'. 
Table 1

Summary of Meta-Analytic Findings for Effect Sizes and Heterogeneity (N = 15 Studies)

\begin{tabular}{|c|c|c|c|c|c|c|c|c|}
\hline Predictor & Outcome & $\begin{array}{c}\mathrm{N} \\
\text { effects }\end{array}$ & Included studies & $\begin{array}{l}\text { Combined } \\
\text { N of } \\
\text { participants }\end{array}$ & r $(95 \% \mathrm{CI})$ & $\begin{array}{l}p \text { value } \\
\text { for } \mathbf{r}\end{array}$ & $I^{2}(95 \% \mathrm{CI})$ & $\begin{array}{l}\text { Higher bonding } \\
\text { associated with } \\
\text { more optimal } \\
\text { outcome }\end{array}$ \\
\hline $\begin{array}{l}\text { Antenatal and post } \\
\text { bonding }^{\mathrm{a}}\end{array}$ & Attachment $^{\mathrm{b}}$ & 4 & $\begin{array}{c}\text { Benoit, Parker, and Zeanah } \\
\text { (1997); Crawford and Benoit } \\
\text { (2009); } \\
\text { Hall et al. (2015); } \\
\text { Huth- Bocks et al. (2011) }\end{array}$ & 477 & $.35(.16, .52)$ & $.001 * *$ & $78(21,99)$ & $\begin{array}{l}\text { More secure } \\
\text { attachment }\end{array}$ \\
\hline Antenatal bonding on & $\begin{array}{l}\text { Attachment: Secure/insecure } \\
\text { classifications only }\end{array}$ & 2 & $\begin{array}{l}\text { Benoit et al. (1997); } \\
\text { Huth- Bocks et al. (2011) }\end{array}$ & 232 & $.30(-.04, .58)$ & .080 & $85(24,100)$ & $\begin{array}{l}\text { More secure } \\
\text { attachment }\end{array}$ \\
\hline Antenatal bonding & Colic/non-colic & 2 & $\begin{array}{c}\text { Escallier (1995); } \\
\text { Pinkus (1979) }\end{array}$ & 141 & $.22(.03, .39)$ & $.025 *$ & $15(0,100)$ & Lower colic rating \\
\hline $\begin{array}{l}\text { Antenatal and postnatal } \\
\text { bonding }\end{array}$ & $\begin{array}{l}\text { Social-emotional } \\
\text { outcomes }^{\mathbf{b}} \text { : Exploratory } \\
\text { activity, negative affect, } \\
\text { positive affect, solicitation of } \\
\text { attention, } \\
\text { social-emotional competence, } \\
\text { externalising behaviours, and } \\
\text { internalising behaviours }\end{array}$ & 9 & $\begin{array}{l}\text { Huth- Bocks et al. (2011); } \\
\text { Mason et al. (2011); } \\
\text { Sierau et al. (2016) }\end{array}$ & 706 & $.13(-.13, .37)$ & .163 & $71^{\mathrm{c}}$ & $\begin{array}{c}\text { More optimal } \\
\text { social-emotional } \\
\text { behaviours }\end{array}$ \\
\hline $\begin{array}{l}\text { Antenatal and postnatal } \\
\text { bonding }^{\mathrm{a}}\end{array}$ & $\begin{array}{l}\text { Temperamental } \\
\text { difficulty }^{\text {bd }} \text { : Activity, } \\
\text { adaptability, approach, } \\
\text { distractibility, intensity, }\end{array}$ & 36 & $\begin{array}{c}\text { Davoudi (2012); } \\
\text { Della Vedova (2014); } \\
\text { Hammarberg (2006); } \\
\text { Jones (1996); }\end{array}$ & 749 & $.19(.03, .34)$ & $.029 *$ & $74^{\mathrm{c}}$ & $\begin{array}{l}\text { Easier overall } \\
\text { temperament }\end{array}$ \\
\hline
\end{tabular}

This article is protected by copyright. All rights reserved 


\begin{tabular}{|c|c|c|c|c|c|c|c|c|}
\hline s. & $\begin{array}{l}\text { mood, persistence, } \\
\text { rhythmicity, sensory } \\
\text { threshold }\end{array}$ & & $\begin{array}{l}\text { arfitt, Ayers, Pike, Jessop, } \\
\text { and Ford (2014); } \\
\text { Priel and Besser (2000); } \\
\text { White et al. (1999) }\end{array}$ & & & & & \\
\hline Antenatal bonding on & $\begin{array}{l}\text { Temperament: } \\
\text { Activity only }\end{array}$ & 3 & $\begin{array}{c}\text { Davoudi (2012); } \\
\text { Della Vedova (2014); } \\
\text { Hammarberg (2006) }\end{array}$ & 298 & $.18(-.43, .67)$ & .583 & $96(86,100)$ & $\begin{array}{c}\text { Normal levels of } \\
\text { activity (not } \\
\text { overactive) }\end{array}$ \\
\hline Antenatal bonding & $\begin{array}{l}\text { Temperament: } \\
\text { Adaptability only }\end{array}$ & 4 & $\begin{array}{c}\text { Davoudi (2012); } \\
\text { Della Vedova (2014); } \\
\text { Hammarberg (2006); } \\
\text { Priel and Besser (2000) }\end{array}$ & 416 & $.23(-.04, .47)$ & .092 & $86(50,99)$ & $\begin{array}{c}\text { More adaptable } \\
\text { (easier to modify } \\
\text { reactions to stimuli } \\
\text { in a desired way) }\end{array}$ \\
\hline Predictor & Outcome & $\mathbf{N}$ effects & Included studies & $\begin{array}{l}\text { Combined } \\
\quad \mathrm{N} \text { of } \\
\text { participants }\end{array}$ & $\mathbf{r}(95 \% \mathrm{CI})$ & $\begin{array}{l}\text { p value } \\
\text { for } r\end{array}$ & $I^{2}(95 \% \mathrm{CI})$ & $\begin{array}{c}\text { Higher bonding } \\
\text { associated with } \\
\text { more optimal } \\
\text { outcome }\end{array}$ \\
\hline Antenatal bonding on & $\begin{array}{l}\text { Temperament: } \\
\text { Approach only }\end{array}$ & 4 & $\begin{array}{c}\text { Davoudi (2012); } \\
\text { Della Vedova (2014); } \\
\text { Hammarberg (2006); } \\
\text { Priel and Besser (2000) }\end{array}$ & 418 & $.22(-.04, .45)$ & .102 & $85(48,99)$ & $\begin{array}{c}\text { More approach to } \\
\text { new stimuli }\end{array}$ \\
\hline Antenatal bonding on & $\begin{array}{l}\text { Temperament: } \\
\text { Distractibility only }\end{array}$ & 3 & $\begin{array}{c}\text { Davoudi (2012); } \\
\text { Della Vedova (2014); } \\
\text { Hammarberg (2006) }\end{array}$ & 303 & $.17(-.05, .37)$ & .135 & $69(0,99)$ & $\begin{array}{l}\text { More able to } \\
\text { distract from } \\
\text { fussing }\end{array}$ \\
\hline Antenatal bonding only & $\begin{array}{l}\text { Temperament: } \\
\text { Intensity only }\end{array}$ & 4 & $\begin{array}{c}\text { Davoudi (2012); } \\
\text { Della Vedova (2014); } \\
\text { Hammarberg (2006); } \\
\text { Priel and Besser (2000) }\end{array}$ & 418 & $.09(-.19, .35)$ & .524 & $87(57,99)$ & $\begin{array}{c}\text { Less intense (less } \\
\text { high energy } \\
\text { responses) }\end{array}$ \\
\hline Antenatal bonding only & Temperament: & 5 & Davoudi (2012); & 480 & $.27(.07, .45)$ & $.009 * *$ & $79(36,98)$ & More positive \\
\hline
\end{tabular}

This article is protected by copyright. All rights reserved 
Hammarberg (2006);

Priel and Besser (2000);

White et al. (1999)

\begin{tabular}{|c|c|c|c|c|c|c|c|c|}
\hline 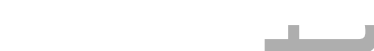 & & & White et al. (1999) & & & & & \\
\hline Antenatal bonding only & $\begin{array}{l}\text { Temperament: } \\
\text { Persistence only }\end{array}$ & 3 & $\begin{array}{c}\text { Davoudi (2012); } \\
\text { Della Vedova (2014); } \\
\text { Hammarberg (2006) }\end{array}$ & 303 & $.19(-.02, .38)$ & .074 & $66(0,99)$ & $\begin{array}{c}\text { More } \\
\text { persistent/attentive } \\
\text { temperament }\end{array}$ \\
\hline Antenatal bonding c & $\begin{array}{l}\text { Temperament: } \\
\text { Rhythmicity only }\end{array}$ & 4 & $\begin{array}{c}\text { Davoudi (2012); } \\
\text { Della Vedova (2014); } \\
\text { Hammarberg (2006); } \\
\text { Priel and Besser (2000) }\end{array}$ & 418 & $.14(-.02, .3)$ & .095 & $63(0,97)$ & $\begin{array}{c}\text { More regular } \\
\text { physiologic } \\
\text { functions, such as } \\
\text { sleep and hunger }\end{array}$ \\
\hline Antenatal bonding only & $\begin{array}{l}\text { Temperament: } \\
\text { Sensory threshold only }\end{array}$ & 3 & $\begin{array}{c}\text { Davoudi (2012); } \\
\text { Della Vedova (2014); } \\
\text { Hammarberg (2006) }\end{array}$ & 303 & $.14(-.49, .68)$ & .683 & $97(88,100)$ & $\begin{array}{c}\text { High threshold } \\
\text { (more stimulation } \\
\text { required to evoke a } \\
\text { response) }\end{array}$ \\
\hline
\end{tabular}

Note. $\mathrm{N}=$ total number; $\mathrm{r}=$ mean effect size; $\mathrm{CI}=$ confidence interval; $\mathrm{I}^{2}=$ indicator of heterogeneity in percentages.

${ }^{a}$ Only one postnatal effect was available and included in this meta-analysis.

${ }^{\mathrm{b}}$ This meta-analysis was a superordinate meta-analysis. See Supporting Information Table S4 for further information on included infant outcomes.

${ }^{\mathrm{c}}$ CIs not available for $\mathrm{I}^{2}$ when using the Robumeta package in $\mathrm{R}$.

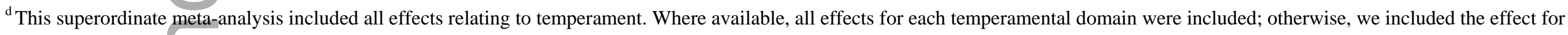
total temperamental difficulty.

$* \mathrm{p}<.05, * * \mathrm{p}<.01$

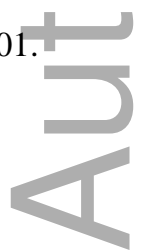

This article is protected by copyright. All rights reserved 


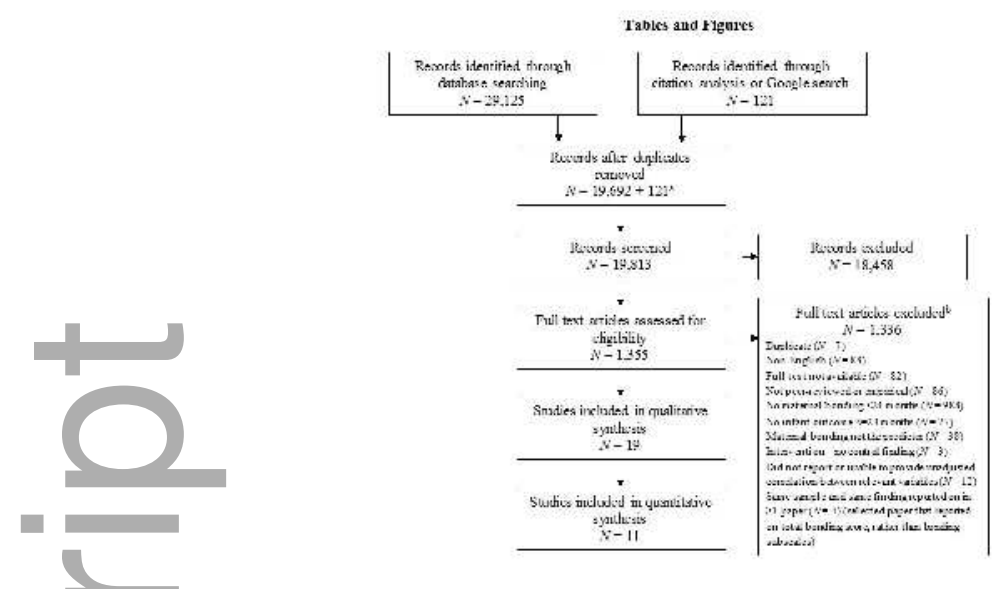

sode_12392_f1.jpg

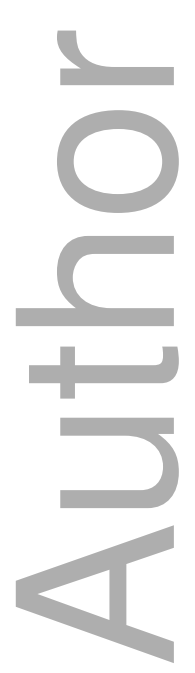

This article is protected by copyright. All rights reserved 


\section{University Library}

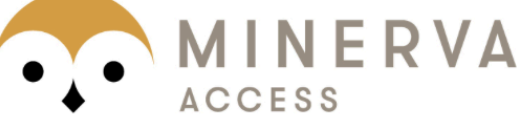

A gateway to Melbourne's research publications

Minerva Access is the Institutional Repository of The University of Melbourne

Author/s:

Le Bas, GA;Youssef, GJ;Macdonald, JA;Rossen, L;Teague, SJ;Kothe, EJ;McIntosh, JE;Olsson, CA;Hutchinson, DM

Title:

The role of antenatal and postnatal maternal bonding in infant development: A systematic review and meta-analysis

Date:

2019-08-14

Citation:

Le Bas, G. A., Youssef, G. J., Macdonald, J. A., Rossen, L., Teague, S. J., Kothe, E. J., Mclntosh, J. E., Olsson, C. A. \& Hutchinson, D. M. (2019). The role of antenatal and postnatal maternal bonding in infant development: A systematic review and meta-analysis. SOCIAL DEVELOPMENT, 29 (1), pp.3-20. https://doi.org/10.1111/sode.12392.

Persistent Link:

http://hdl.handle.net/11343/286906 